\title{
Survey of Internet Use as a Source of Health-Related Information in Qassim Province, Saudi Arabia
}

\author{
IA Alwehaibi ${ }^{1}$ and AA Almeman ${ }^{2 *}$ \\ ${ }^{1}$ Buraidah Central Hospital, ${ }^{2}$ Pharmacy School, Almulaida, Qassim University, Qassim, Kingdom of Saudi Arabia
}

${ }^{*}$ For correspondence: Email: ahmadalmeman@gmail.com; Tel: 00966548889712; Fax: 0096663800662

Received: 16 October 2013

Revised accepted: 14 June 2014

\begin{abstract}
Purpose: To estimate the proportion of patients in Qassim Province, Saudi Arabia, who use the Internet to search for health-related information, determine barriers to Internet use, and investigate the relationship between Internet use and socio-demographic variables.

Methods: A total of 377 questionnaires were distributed to five main hospitals in Qassim Province (Saudi Arabia). The patients were randomly selected to complete the survey when they arrived to fill their pharmacy prescription. The survey was explained to the patients, and they were given the option to participate or decline.

Results: Fifteen percent of the respondents used the Internet as a source of health-related information, especially disease-specific information (97.7 \%). Thirty percent used the Internet after a recommendation from their health-care provider. The highest proportions of respondents indicated that lack of training and the cost of Internet access were major barriers to Internet use. There was a significant association between Internet use and education level ( $p=0.002)$.

Conclusion: Compared with published data for Qassim City, Saudi Arabia, Internet use to obtain health-related information is relatively low in the Qassim Province, Saudi Arabia. Lack of training is the most common barrier.
\end{abstract}

Keywords: Health information, Barriers, Internet use, Patient and internet, Saudi Arabia

\begin{abstract}
Tropical Journal of Pharmaceutical Research is indexed by Science Citation Index (SciSearch), Scopus, International Pharmaceutical Abstract, Chemical Abstracts, Embase, Index Copernicus, EBSCO, African Index Medicus, JournalSeek, Journal Citation Reports/Science Edition, Directory of Open Access Journals (DOAJ), African Journal Online, Bioline International, Open-J-Gate and Pharmacy Abstracts
\end{abstract}

\section{INTRODUCTION}

The accessibility of the Internet and the variety of information on the World Wide Web has expanded the availability of health-related information, including in the Middle East [1]. Patients with life-threatening diseases often turn to the Internet for medical information [2]. Searching for health information or a desire to obtain health information depends on the health status of the person, including the fear of becoming ill or a desire to avoid becoming ill [3]. Searching for health-related information is one of the chief reasons that patients go online. Quantitative surveys [4] and qualitative research
[5] provide evidence of the significance of online searches as a source of health information and as an activity that affects health, relationships with doctors, a patient's lifestyle, and how treatment is located [6-8]. Several factors may contribute to choosing the Internet as a source of health-related information. People who adopt and use this communication technology are typically younger, better educated, and have higher incomes [9]. Another factor that affects the degree of Internet use is experience. The more experienced individual is more likely to use the Internet [10]. 
This study aimed to determine the proportion of patients who use the Internet to search for health-related information in Qassim Province, Saudi Arabia, and to identify barriers to using the Internet for this purpose. We also investigated the effect of socio-demographic variables on Internet use.

\section{EXPERIMENTAL}

A four-part survey $(n=377)$ was distributed to five hospitals in the Qassim Province, Saudi Arabia, each of which was a major hospital in the region. The first part of the survey was designed to collect demographic characteristics of the respondents. It included questions on gender, nationality, age, employment level and status, family income, and marital status. The second part included four questions about using the Internet to obtain health-related information. The third part of questionnaire included seven statements regarding the most crucial barriers to Internet use. The fourth part of the survey asked the respondents to write any additional comments. Study approval was obtained from the Buraidah Central Hospital (Qassim Province, Saudi Arabia), main pharmacy.

The target study population was patients who used the Internet and visited Ministry of Health $(\mathrm{MOH})$ hospitals in the Qassim Province, Saudi Arabia. These hospitals included Buraidah Central Hospital, King Fahad Specialists Hospital, Maternity and Children's Hospital, all located in Buraidah, King Saud Hospital (Unaizah) and (5) Albukairyah General Hospital (Albukairyah). A stratified random sample of eligible inpatients and outpatients was selected at each hospital. The random sampling was selected from patients visiting to receive their pharmacy prescription. All patients were asked to complete the questionnaire. Patients that consented were given the survey and a cover letter that explained how to complete the questions.

\section{Statistical analysis}

Questionnaire items were developed after a literature review. Input by experts was used during the development of the final draft to ensure readability and ease of completion. Survey validation consisted of a pilot study using 25 patients who were not included in the main study. Statistical Package for Social Science (SPSS, IBM, Armonk, NY, USA) software was used for the data analysis. The descriptive data analysis included the estimation of frequencies, proportions, means, standard deviations, and Chi-square tests for association. Results were considered to be statistically significant at $p<$ 0.05 .

\section{RESULTS}

Eighty-six percent (325/377) of the surveys were completed. The mean age of the respondents was $33 \pm 11.5$ years. A high percent $(38 \%)$ were $>35$ years of age, and greater than one-half were male $(59.7 \%)$. The majority $(62.5 \%)$ of respondents were married, and only $2.8 \%$ were of non-Saudi nationality. Twenty percent of patients $<25$ years of age, $48.8 \%$ between 25 and 35 years of age and $31.1 \%>35$ years of age used the Internet for health purposes. Sixtythree percent were university students or graduates, $29 \%$ were high school graduates, and the remainder did not complete high school. About one-half of the respondents (53.5\%) were employed. Monthly income was $<3000$ SR for 15 $\%, 3000$ to 6000 SR for $40.6 \%$, and $>6000$ SR for $44 \%$ of the respondents.

Fifteen percent of the respondents had obtained health-related information from the Internet. Thirty percent who had used the Internet did so after a recommendation from their health-care provider, but it had not been recommended as a resource to $70 \%$ of the respondents who used it. Fifty percent of those who used the Internet also received health-related information from other patients and $23 \%$ received it from television or radio. Fifteen percent reported receiving health information from newspapers.

The highest proportions of patients that used the Internet were searching for disease-related (97.7 $\%$ ) and for medication-related (52 \%) information. Some patients (34\%) used the Internet to obtain a second opinion while others $(13.6 \%)$ used it to find information about health-care facilities. Only $4.5 \%$ used it to obtain information about healthcare staff. Analysis of the frequency-of-use results revealed that in the 3 months before completing the survey, $88.6 \%$ and $11.4 \%$ performed health-related searches 1 to 5 times and 6 to 8 times, respectively. No patient reported conducting health-related Internet searches $>10$ times.

\section{Barriers to internet use}

The highest proportions of respondents indicated that lack of training and cost of Internet access were the major barriers to Internet use (Table 1). The inability to read and write English, mistrust of health information on the Internet, and not having a computer were additional barriers. 
Table 1: Barriers to Internet use

\begin{tabular}{lccc}
\hline Statement & Agree & Neutral & Disagree \\
\hline Don't have a computer & $59 \%$ & $3 \%$ & $38 \%$ \\
Don't have training on Internet use & $82 \%$ & $3 \%$ & $15 \%$ \\
Afraid about my privacy & $25 \%$ & $12 \%$ & $62 \%$ \\
Don't have time & $32 \%$ & $14 \%$ & $54 \%$ \\
The cost of Internet access & $73 \%$ & $7 \%$ & $20 \%$ \\
Inability to read and write English & $66 \%$ & $7 \%$ & $27 \%$ \\
Mistrust of health information on the Internet & $59 \%$ & $5 \%$ & $36 \%$ \\
\hline
\end{tabular}

Relationship between internet use and sociodemographic variables

There were no associations between Internet use for health-related purposes and age $(p=0.142)$, sex $(p=0.7)$, marital status $(p=0.5)$, employment status $(p=0.1)$, or monthly income $(p=0.4)$. There was, however, a statistically significant association between Internet use and education level $(p=0.002)$.

\section{DISCUSSION}

The topic of patient use of the Internet to obtain health-related information is currently of great interest worldwide. The growth in Internet availability in Saudi Arabia has been accompanied by an expansion in the number of medical and other health-related websites, which in turn has increased the use of the Internet as a source for health-related information. This access to information may help patients to better manage their illnesses and to make informed choices. Understanding the barriers to Internet use will help to eliminate them in the future.

In this study, $15 \%$ of the respondents used the Internet for health-related information. Other studies have reported estimates of $50 \%$ to $75 \%$ [11-13]. The population in Saudi Arabia uses the Internet very modestly compared with other populations. Fifteen percent of those who used the Internet had received information about their health status from other patients. This finding is consistent with the result of another survey conducted in Saudi Arabia in 2006, which indicated that $36 \%$ of patients receive information about their illness from other patients [14]. Healthcare providers should consider the effect that information from other patients may have on patient compliance and treatment outcomes.

Seventy percent of the patients did not receive any recommendations about Internet use from their healthcare providers. Healthcare staff may not be familiar enough with the Internet to recommend websites. However, a 2012 poll by Cyber Dialogue found that $70 \%$ of patients want their physicians to recommend websites, but only $4 \%$ receive any recommendations [11]. Physicians should discuss this issue with their patients to avoid potential misuse of website information.

Among patients who used the Internet, $97.7 \%$ searched for disease-related information and 52 $\%$ searched for medication-related information. Schwartz et al reported similar results from a USA study. Respondents searched for diseasespecific information $79 \%$ of the time, followed by medication information (53\% of searches), and information about nutrition and exercise [15]. Our patients were more interested in searching for disease-related information than the patients in the Schwartz et al study. However, the proportion of patients who used the Internet in our study was much lower than the proportion in their study.

A high proportion of patients $(88.6 \%)$ in this study used the Internet for health-related objectives 1 to 5 times in the previous 3 months. This result is similar to the result reported by a nationwide Harris poll in the USA in 2012, which found that respondents searched for healthrelated information online an average of 3.3 times per month [11].

Eighty-two percent considered lack of training to be a major barrier to Internet use, vs. $19 \%$ reported in Europe [16]. The cost of Internet access was another major barrier. A previous survey in Saudi Arabia reported that the cost of access is considered to be a barrier by a much lower proportion (31.8\%) of participants [17]. We found no significant relationships between Internet use and age, sex, nationality, employment status, or monthly income. There was a significant relationship between Internet use and education level, which was consistent with results for a US population [18]. Education level might increase patient awareness and allow 
them to seek further information or might improve computer use skills.

\section{Limitations of the study}

The major limitation of this study was that the study population consisted of individuals who had been diagnosed with an illness, so the results may not be representative of the general (i.e., healthy) population. However, information from this population is valuable because individuals who are ill have the most incentive to search online for health-related information. Further work will determine whether their Internet use represents the Internet use the general population in Saudi Arabia.

\section{CONCLUSION}

Internet use for health purposes by patients in Qassim Province, Saudi Arabia is low compared with other countries. The real effect of this difference is unknown. The Ministry of Health in Saudi Arabia should plan and implement a nationwide program to educate patients about computer and Internet use. The program should include a strategy to overcome barriers to Internet access and increase awareness of the websites that have the highest quality information.

\section{REFERENCES}

1. Internet world statistics: usage and population statistic. Updated 2012; [Cited December 2012] available from:

http://www.internetworldstats.com/middle.htm/\#sa.

2. Nua Internet Surveys. How many online? Updated 2012; [Cited 6 December 2012] available from: http://www.nua.com/surveys/how_many_online/index. html.

3. Becker MH, Maiman LA. Socio-behavioral determinants of compliance with health and medical care recommendations. Med Care 1975; 13: 10-24.

4. Madden M, Fox S. Finding Answers Online In Sickness And In Health. Updated 2012; [Cited November 2012]; Pew Internet \& American Life Project. Available from: http://pewinternet.org/pdfs/PIP_health _Decisions 2006. pdf
5. Reents S. "Impacts of the Internet on the Doctor Patient Relationship: The Rise of the Internet Health Consumers. Cyber Dialogue. Available from: http//www.cyberdialogue.com/pdfs/wp/wp-cch-1999doctors.pdf.

6. Williams $P$, Nicholas $D$, Huntington $P$. Health Information On The Internet: 'A Qualitative Study of NHS Direct Online Users'. Aslib Proceedings. New Information Perspectives. 2003; 55(5-6): 304-312.

7. Orgad S. Storytelling Online: Talking Breast Cancer In The Internet. Peter Lang. New York; 2005.

8. Seale C. New Direction For Critical Internet Health Studies: Representing Cancer Experience on The Web. Social Health 2005; 27(4): 515-540.

9. Lin CA. Perceived Gratifications of Online Media Services Use Among Potential Users. Telematics Informatics 2002: 19:3-19.

10. Boyer C, Provost M, Baujard V. Highlights Of The 8th HON Survey Of Health And Medical Internet Users. Health on the Net Foundation. [Updated 2012; cited in 2012]. Available from: http://www.hon.ch/Survey/8th_HON_results.html.

11. Taylor H. The Harris Poll. Cyberchondriacs [Updated 2012; cited1 December 2012] URL: Available from: http://www.harrisinteractive.com/harris_poll/index.asp

12. Tatsumi H, Mitani H, Haruki Y, Ogushi Y. Internet Medical Usage In Japan: Current Situation And Issues. J Med Internet Resourses. 2001; 3(1): e12.

13. Murero $M$, D'ancona $G$, Karamanoukian $H$. Use of the Internet by patients before and after cardiac surgery: telephone survey. J Med Internet Res 2001 Sep 30; 3(3): e27.

14. Ezzeldin MI, Boulos MNK. Access to Online Information by Adult Saudi Cancer Patients. Internet $J$ Health. 2006; 5(1): 4 Available from: http://ispub.com/IJMI/ 2/2/10232

15. Schwartz, KL, Roe TJ, Northhup J, Meza J, Seifeldin R, Neale AV. Family Medicine Patients Use Of The Internet. Board of Family Medicine 2006; vol. 19 pp 39-45.

16. Health on the net foundation. HON code of conduct for Medical and Health web sites. [4 November 2012]. Available from: http://www.hon.ch/HONcode/ Conduct.html

17. Sait SM., Al-Tawil KM. Impact on Internet Usage in Saudi Arabia: A Social Perspective. Int J Inform Technol Web. 2007 Jun; 2(2): 81-115.

18. Baker L, Wagner TH, Singer S, Bunduorf MK. Use Of The Internet And Email For Health Care Information: National Survey Results. JAMA. 200; 289: 18: 24002406. 